\title{
Qualidade do maracujá amarelo fertirrigado com nitrogênio e substâncias húmicas
}

\author{
Roberto Lustosa Silva', Ítalo Herbert Lucena Cavalcante ${ }^{2}$, Karla dos Santos Melo de Sousa, ${ }^{2}$ \\ Cristiane Xavier Galhardo², Elisson Alves Santana², Deisiele Diniz Lima² \\ 'Universidade Federal de Viçosa, Viçosa, Brasil \\ ${ }^{2}$ Universidade Federal do Vale do São Francisco, Petrolina, PE, Brasil \\ *Autor correspondente, e-mail: elisson.uneb@hotmail.com
}

\section{Resumo}

A qualidade de frutos de maracujazeiro é influenciada por fatores genéticos e exógenos à planta como clima, o solo e as práticas culturais, incluindo adubação e irrigação. Nesse sentido, um experimento foi desenvolvido de fevereiro a dezembro de 2013 para avaliar o efeito da fertirrigação com nitrogênio e substâncias húmicas na qualidade física e química do maracujá amarelo em Juazeiro-BA. O delineamento experimental usado foi em blocos casualizados com parcelas subdivididas, adotando-se nas parcelas cinco doses de N (180, 200, 260, 330 e $350 \mathrm{~kg} \mathrm{ha}^{-1}$ de N), e nas subparcelas o uso de substâncias húmicas (sem e com), com cinco repetições e seis plantas por parcela. Aos 210 dias após o transplantio os frutos foram colhidos e conduzidos ao laboratório para avaliação de massa fresca, diâmetros longitudinal e transversal do fruto, espessura de casca, percentagem de polpa, pH da polpa, vitamina C, acidez titulável, sólidos solúveis e relação sólidos solúveis/acidez titulável (ratio). Os frutos produzidos, independentemente do tratamento, são adequados para o consumo in natura e/ou e para indústria. Recomenda-se a dose de $260 \mathrm{~kg} \mathrm{ha}^{-1}$ de $\mathrm{N}$ sem substâncias húmicas para a produção de frutos de maracujá-amarelo com qualidade.

Palavras-chave: Passiflora edulis Sims, ácidos húmicos, pós-colheita

\section{Fruit quality of yellow passion fruit fertilized with nitrogen and humic substances}

\begin{abstract}
The quality of yellow passion fruits is affected by genetic and exogenous factors like climate, soil and agricultural practices such as fertilizing and irrigation. Thus, an experiment was developed from February to December 2013 to evaluate the effect of nitrogen fertigation and humic substances on physical and chemical quality of yellow passion fruits. The experimental design used was in complete blocks design with subdivided plots with $\mathrm{N}$ rates $\left(180,200,260,330\right.$ and $350 \mathrm{~kg} \mathrm{ha}^{-1}$ year ${ }^{-1}$ ) in parcels and application of humic substances (with and without) in sub-parcels, with five repetitions of six plants. At 210 days after transplanting all fruits were harvested and conducted to the laboratory for evaluation of fruit mass, longitudinal and transversal fruit diameter, skin thickness, pulp percentage, pulp pH, vitamin C, soluble solids, titratable acidity, and soluble solids/titratable acidity ratio. Fruits produced, independently of the treatment, are adequate for consumption as in natura or processed fruit. It is possible to recommend a dose of $260 \mathrm{~kg} \mathrm{ha}^{-1}$ of $\mathrm{N}$ without humic substances for production of good quality yellow passion fruits.
\end{abstract}

Key words: Passiflora edulis Sims, post-harvest, humic acids 


\section{Introdução}

O maracujazeiro amarelo (Passiflora edulis Sims) é a principal espécie da família Passifloraceae cultivada no Brasil, devido às características físico-químicas dos frutos, alta produtividade e grande aceitação do suco no mercado nacional (Cavichioli et al., 201 1; Santos et al., 2014).

O Brasil com produção de 776.097toneladas e rendimento médio de 13,42† ha-1 $^{-1}$ é referência na produção de maracujá, destacando-se a região nordeste com 72,59\% da produção nacional e quantidade produzida de 563.346 toneladas. O estado da Bahia lidera o ranking com 320.945 toneladas de frutos produzidos, favorecido pelas condições de solo e clima observado nessa região (IBGE, 2014).

Os frutos do maracujazeiro-amarelo para consumo in natura são preferíveis àqueles que atendam às exigências de qualidade dos diferentes segmentos de consumidores, nas características internas quanto ao sabor (teor de açúcares e acidez) e conteúdo de suco (rendimento); e externas no que se refere à aparência, característica associada aos parâmetros de padronização da fruta é geralmente usado como critério pelos consumidores para avaliar a qualidade dos frutos (Abreu et al., 2009; Rocha et al., 2013).

A qualidade de frutos de maracujazeiro é influenciada por fatores genéticos e exógenos à planta como clima, o solo e as práticas culturais, incluindo adubação e irrigação (Cavalcante et al., 2012a e 2012b; Rocha et al., 2013). Os nutrientes devem ser aplicados em níveis compatíveis com as exigências da planta e com a forma de adubação utilizada, destacando-se que a aplicação via água de irrigação, fertirrigação, é atualmente de comprovada eficácia (Borges et al., 2006).

Dentre os nutrientes essenciais, relevase o nitrogênio (N) por participar de diversos compostos indispensáveis para o crescimento e o desenvolvimento das plantas, destacando-se as proteínas e as clorofilas além de ser constituinte de bases nitrogenada e ácidos nucléicos (Taiz \& Zeiger, 2009). Segundo Bredemeier \& Mundstock (2000) a quantidade extraída de N varia durante o ciclo de desenvolvimento da planta, dentre as formas nas quais o nitrogênio é absorvido pelas plantas, as mais importantes são a nítrica e amoniacal.

Objetivando incrementar a eficiência da absorção de nutrientes, principalmente - $N$ tem-se estudado além doadequado manejo da irrigação e fertirrigação o uso de substâncias húmicas que apresentam influência amplamente reconhecida nas propriedades químicas, físicas e biológicas do solo (Loss et al., 2015) e, consequentemente, no crescimento radicular das plantas, aumento na absorção de nutrientes e a biossíntese de clorofilas (Ferrara \& Brunetti, 2008; Baldotto et al., 2009; Cavalcante et al., 2012b; Cavalcante et al., 2014).

Assim, o objetivo deste trabalho foi avaliar o efeito na qualidade física e química do maracujá amarelo produzido em JuazeiroBA em função de fertirrigação com nitrogênio e substâncias húmicas.

\section{Material e Métodos}

O experimento foi desenvolvido de fevereiro a dezembro de 2013, no núcleo habitacional 02 do perímetro irrigado Curaçá, situado no município de Juazeiro-BA e localizado às coordenadas geográficas latitude: $09^{\circ} 07^{\prime} \mathrm{S}$, longitude: $40^{\circ} 04^{\prime} \mathrm{W}$ com altitude de $376 \mathrm{~m}$. O clima da região é classificado, segundo Köppen, como semiárido quente e seco (Bswh).

As características químicas e físicas do solo da área experimental encontram-se na (Tabela 1), enquanto que os dados referentes às variáveis climáticas, temperatura e umidade relativa do ar e precipitação durante a execução do experimento encontram-se na Figura 1.

As mudas foram transplantadas em fevereiro de 2013, em espaçamento de $3 \times 3$ $\mathrm{m}$, para covas não adubadas e conduzidas em espaldeira vertical, com um fio de arame liso $n^{\circ} 14$, a 1,8 m em relação ao solo. A irrigação foi realizada diariamente pelo método de aplicação localizada por gotejamento, fornecendo-se, diariamente, uma lâmina de 12,8 $\mathrm{mm}$, equivalente à evaporação diária corrigida de acordo com o coeficiente de cultura $(\mathrm{KC})$ do maracujazeiro.

A fonte de nitrogênio utilizada foi ureia (45\% de N) com adubações semanais, a partir 
dos 30 dias após o transplantio (DAT) segundo recomendação de Borges \&Coelho (2009). Foram feitas ainda adubações com fósforo e potássio, utilizando-se como fontes o fosfato monoamônico MAP $\left(50 \%\right.$ de $\left.\mathrm{P}_{2} \mathrm{O}_{5}\right)$ e cloreto de potássio $\left(60 \% \quad \mathrm{~K}_{2} \mathrm{O}\right)$ respectivamente. A adubação fosfatada $120 \mathrm{~kg} \mathrm{P}_{2} \mathrm{O}_{5} \mathrm{ha}^{-1} \mathrm{ano}^{-1}$ foi parcelada em duas aplicações, aos 90 e 210 DAT. O potássio (140 kg K $\mathrm{O} \mathrm{ha}^{-1} \mathrm{ano}^{-1}$ ) foi parcelado semanalmente a partir dos 90 DAT. As adubações foliares com fontes de micronutrientes foram realizadas a cada 15 dias a partir dos 90 DAT.

Tabela 1. Características químicas, físicas e os estoques de carbono no solo antes da implantação do experimento no perfil de 0-30 cm de profundidade.

\begin{tabular}{|c|c|c|c|}
\hline Atributos Químicos & Valor & Atributos Físicos & Valor \\
\hline $\mathrm{pH}$ (em água- $1: 2,5$ ) & 5,6 & Areia $\left(\mathrm{g} \mathrm{kg}^{-1}\right)$ & 657,90 \\
\hline$P\left(\mathrm{mg} \mathrm{dm}^{-3}\right)$ & 10,0 & Silte $\left(\mathrm{g} \mathrm{kg}^{-1}\right)$ & 277,30 \\
\hline $\mathrm{K}^{+}\left(\mathrm{cmolcdm}^{-3}\right)$ & 0,28 & Argila $\left(\mathrm{g} \mathrm{kg}^{-1}\right)$ & 64,80 \\
\hline $\mathrm{Ca}^{2+}\left(\mathrm{cmolcdm}^{-3}\right)$ & 3,5 & $\mathrm{DS}\left(\mathrm{kg} \mathrm{dm}^{-3}\right)$ & 1,52 \\
\hline $\mathrm{Mg}^{2+}\left(\mathrm{cmolcdm}^{-3}\right)$ & 1,5 & $\mathrm{DP}\left(\mathrm{kg} \mathrm{dm}^{-3}\right)$ & 2,51 \\
\hline $\mathrm{Na}^{+}\left(\mathrm{cmolcdm}^{-3}\right)$ & 0,29 & Porosidade total (\%) & 39,61 \\
\hline SB $\left(\mathrm{cmolcdm}^{-3}\right)$ & 5,57 & Classificação & Franco Arenosa \\
\hline $\mathrm{Al}^{3+}\left(\mathrm{cmolcdm}^{-3}\right)$ & 0,00 & \multicolumn{2}{|c|}{ Estoques de carbono no solo } \\
\hline $\mathrm{H}^{+}+\mathrm{Al}^{3+}\left(\mathrm{cmolcdm}^{-3}\right)$ & 1,60 & \multirow{2}{*}{ Frações } & \multirow{2}{*}{$-\left(t h a^{-1}\right) \amalg$} \\
\hline CTC $\left(\mathrm{cmolcdm}^{-3}\right)$ & 7,17 & & \\
\hline V (\%) & 78 & COT & 6,54 \\
\hline$M O\left(g^{-3}\right)$ & 12,1 & $\mathrm{CFH}$ & 2,41 \\
\hline$C\left(g^{-3}\right)$ & 7,0 & CFAH & 1,11 \\
\hline C.E. $\mathrm{a} 25^{\circ} \mathrm{C}(\mathrm{dS} / \mathrm{m})$ & 2,0 & CFAF & 0,64 \\
\hline
\end{tabular}

P, $\mathrm{K}$ e Na: Extratores: Melich(HCl+ $\mathrm{H} S \mathrm{SO}$ ): Al, $\mathrm{Ca}, \mathrm{Mg}$ : Extrator $\mathrm{KCllM}$ : MO= matéria orgânica: $\mathrm{SB}=$ soma de bases: $\mathrm{V}=$ valor de saturação por bases: $\mathrm{CTC}=$ capacidade de troca de cátions; $\mathrm{DS}=$ Densidade do solo e DP= Densidade de partículas; $C . E .=$ Condutividade elétrica; $C O T=$ Carbone orgânico total; $\mathrm{CFH}$; CFAF e CFAH= Carbono na fração humina, ácido húmico e ácido fúlvico respectivamente
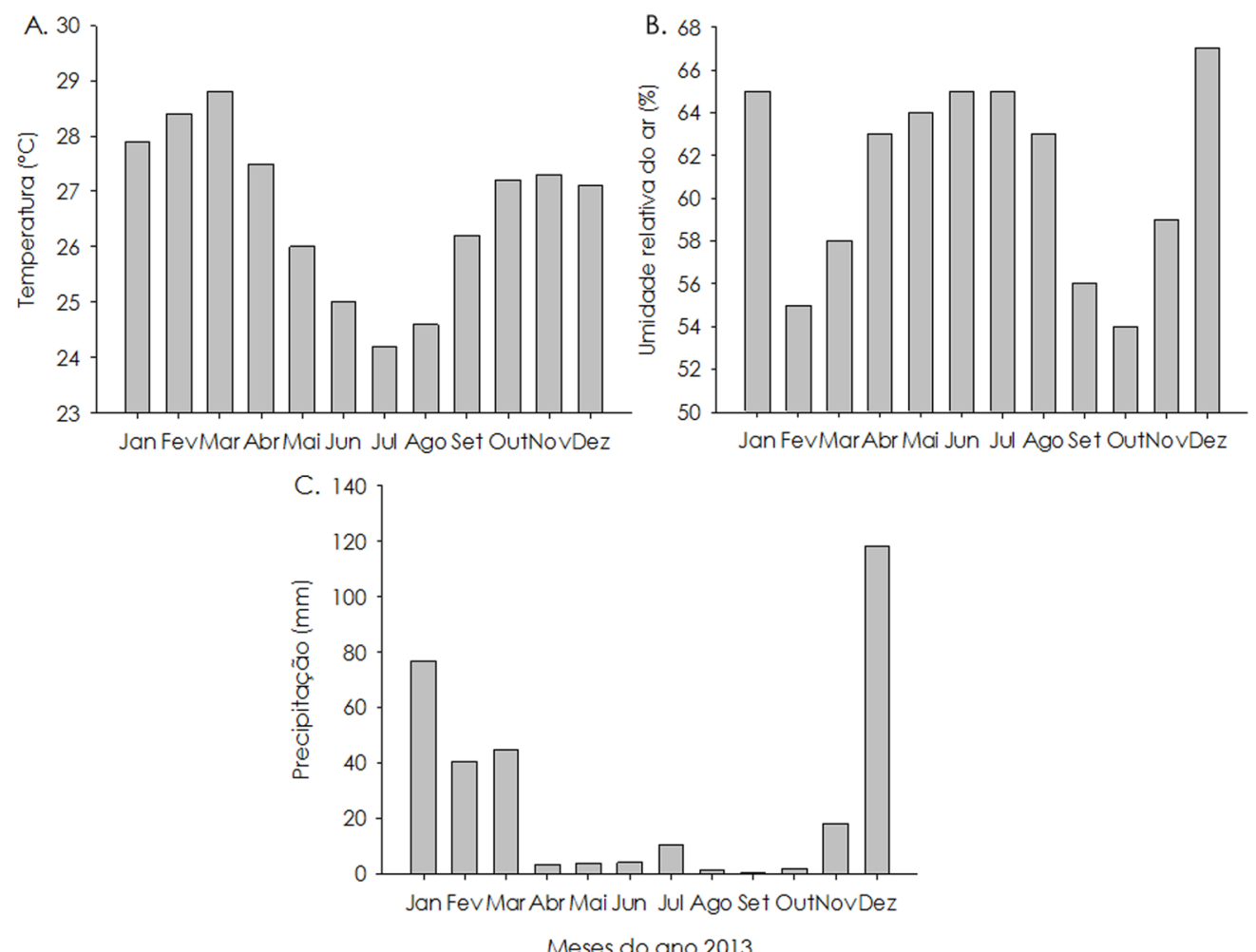

Figura 1. Temperatura (A), umidade relativa do ar (B) e precipitação (C) mensais durante a execução do experimento. 
A fonte de substâncias húmicas (SH) utilizada no experimento, foi o produto comercial KS $100\left(O \mathrm{mnia}^{\circledR}\right)$, proveniente de leonardita, cuja composição $\mathrm{K}_{2} \mathrm{O}(15 \%)$, carbono orgânico total (45\%), ácidos húmicos (70\%), ácidos fúlvicos (8\%), condutividade elétrica $(0,37 \mathrm{~ms} / \mathrm{cm})$, índice salino (24), pH (10) e solubilidade (140 g $\left.\mathrm{L}^{-1}\right)$. As fertirrigações com SH foram realizadas uma vez por mês, seguindo as recomendações do fabricante $\left(5 \mathrm{~kg} \mathrm{ha}^{-1}\right.$ do produto ao longo do ciclo da cultura). Após a diluição segundo a solubilidade de cada insumo, as SHs e fertilizante nitrogenado foram aplicados diretamente na linha de injeção.

O delineamento experimental adotado foi em blocos casualizados com parcelas subdivididas, As parcelas principais foram asdoses de $\mathrm{N}\left(180,200,260,330\right.$ e $350 \mathrm{~kg} \mathrm{ha}^{-1}$ de $\mathrm{N}$ ), e as subparcelas a aplicação de substâncias húmicas (sem e com), com cinco repetições e seis plantas por parcela, para avaliação das quatro centrais. As doses de $\mathrm{N}$ foram definidas segundo as recomendações de Borges \& Coelho (2009).

Os frutos foram colhidos manualmente quando apresentaram pelo menos $25 \%$ da área da superfície externa amarelada, devidamente acondicionados em contentores plásticos e imediatamente conduzidos ao laboratório, onde foram selecionados e padronizados quanto ao tamanho e submetidos à caracterização físicoquímica.

$\begin{array}{lllll} & \text { Avaliaram-se } & 10 \quad \text { (dez) } & \text { frutos } \\ \text { por } & \text { parcelapara } & \text { determinação } & \text { das }\end{array}$
características físico-químicas.As análises físicas compreenderam: i) massa fresca (MF): determinada por pesagem dos frutos individualmente em balança semianalítica, com precisão de $0,1 \mathrm{~g}$; ii) diâmetro longitudinal do fruto (DLF) e diâmetro transversal do fruto (DTF): determinados com auxílio de um paquímetro digital (Digimess $)$, e os resultados expressos em milímetro (mm); iii) espessura de casca (EC): determinada com auxílio de um paquímetro digital (Digimess'), e os resultados expressos em milímetro ( $\mathrm{mm}$ ); e iv) percentagem de polpa (PP): Obtida pela diferença entre a massa do fruto inteiro e a massa da casca.

$$
\text { As análises químicas seguiram a }
$$

metodologia descrita por Instituto Adolfo Lutz (IAL, 2008) e compreenderam: i) pH - determinado em pHmetro (Quimis ${ }^{\circledR}$ ) digital com leitura direta; ii) vitamina $C$ - determinada segundo Baccan et al. (2001): $5 \mathrm{~mL}$ de suco foi previamente diluído em balão volumétrico de $100 \mathrm{~mL}$. Esta solução foi titulada com solução de iodo $0,0300 \mathrm{~mol} \mathrm{~L}^{-1}$ utilizando-se $1 \mathrm{~mL}$ de solução de amido $1 \%$ como indicador. A solução de iodo sofreu padronização prévia. A leitura foi realizada em duplicata e os resultados expressos em mg $100 \mathrm{~mL}^{-1}$; iii) acidez titulável (AT) - pesou-se $1 \mathrm{~g}$ de polpa e diluída em $50 \mathrm{~mL}$ de água destilada. A titulação foi feita com a solução de $\mathrm{NaOH} 0,1 \mathrm{~mol} \mathrm{~L}^{-1}$, utilizando-se a fenolftaleína (1\%) como indicador. A leitura foi realizada em duplicata e os resultados expressos em porcentagem; iv) teor de sólidos solúveis (SS) - determinados por leitura direta em refratômetro de bancada $A B B E^{\circledR}$ com escala de variação de 0 a $95^{\circ}$ Brix; v) Relação SS/AT (ratio) - O ratio foi obtido por meio do quociente entre as variáveis SS e AT.

Os dados foram submetidos à análise de variância (ANOVA) para diagnóstico de efeito significativo entre os tratamentos, pelo Teste "F" e pelo teste de Tukey a $5 \%$ de probabilidade, para comparação das médias das substâncias húmicas no software ASSISTAT, enquanto as doses de $N$ foram avaliadas por regressão simples usando o software SIGMAPLOT.

\section{Resultados e Discussão}

Conforme se pode observar na Tabela 2, não foi verificada interação significativa entre as doses de nitrogênio (N) e substâncias húmicas (SHs) sobre os atributos físicos dos frutos do maracujazeiro-amarelo, do mesmo modo, não foi observado efeito isolado destes fatores sobre nenhum dos atributos físicos avaliados.

Independentemente da fertirrigação com substâncias húmicasé possível observar que a massa de fruto,embora não tenha apresentado diferença significativa entre os tratamentos avaliados (Tabela 2) foi superioraos valores registrados por Cavichioli et al. (2008) que registraram variação de 144 a $149 \mathrm{~g}$ nos frutos de maracujazeiro-amarelo, bem como superiores aos registrados por Borges et al. (2006) que obtiveram 137,8 a 139,7 g em experimento 
testando doses e fontes de nitrogênio em fertirrigação no cultivo do maracujá-amarelo em Latossolo Amarelo no estado da Bahia. A ausência de efeito significativo associada ao registrado no presente estudo pode ser atribuída às condições iniciais de fertilidade do solo onde o experimento foi desenvolvido (Tabela 1), que para a maioria das características atende às exigências do maracujazeiro-amarelo durante a fase de desenvolvimento vegetativo, fato que não, necessariamente ocorreria para o período reprodutivo da cultura.

Tabela 2. Características físicas [massa do fruto (MF), diâmetro transversal (DTF), diâmetro longitudinal (DLF), espessura de casca (EC) e porcentagem de polpa (PP)]de frutos domaracujazeiro-amarelo em função de fertirrigação com nitrogênio e substâncias húmicas.

\begin{tabular}{|c|c|c|c|c|c|}
\hline Fonte de Variação & $\begin{array}{c}M F \\
-\mathrm{g}-\end{array}$ & DTF & $\begin{array}{c}\mathrm{DLF} \\
-\mathrm{mm}-\end{array}$ & $\mathrm{EC}$ & $\begin{array}{l}\text { PP } \\
\%\end{array}$ \\
\hline Substâncias Húmicas & $0,75^{\mathrm{ns}}$ & $1,87^{\mathrm{ns}}$ & $3,344^{\mathrm{ns}}$ & $2,32^{\text {ns }}$ & 3,09 ns \\
\hline Ausência & 209,96 a & $79,74 a$ & 98,02 a & $6,98 \mathrm{a}$ & $40,31 \mathrm{a}$ \\
\hline Presença & $201,69 a$ & $77,36 a$ & $94,96 a$ & $6,29 a$ & $36,51 a$ \\
\hline DMS & 21,90 & 4,01 & 3,84 & 1,04 & 4,97 \\
\hline Doses de N (kg ha-1) & $0,63^{\mathrm{ns}}$ & $0,24^{\text {ns }}$ & $0,64^{\mathrm{ns}}$ & $0,67^{\mathrm{ns}}$ & $1,16^{\mathrm{ns}}$ \\
\hline 180 & 217,37 & 79,81 & 98,26 & 6,97 & 40,91 \\
\hline 200 & 203,75 & 78,62 & 98,35 & 6,41 & 37,73 \\
\hline 260 & 205,59 & 78,27 & 94,43 & 6,93 & 35,87 \\
\hline 330 & 207,58 & 78,07 & 95,47 & 6,70 & 37,71 \\
\hline 350 & 194,85 & 77,99 & 95,95 & 6,19 & 39,85 \\
\hline SHXN & $0,17 \mathrm{~ns}$ & $0,73^{\mathrm{ns}}$ & $0,08^{\text {ns }}$ & $2,37^{\text {ns }}$ & 2,14 ns \\
\hline CV\% & 15,59 & 6,09 & 7,12 & 19,56 & 15,14 \\
\hline
\end{tabular}

Para os diâmetros transversal e longitudinal do fruto e espessura de casca não foi registrado diferença significativa em relação aos tratamentos aplicados (Tabela 2), portanto convergindo com os resultados de Venâncio et al. (2013) ao avaliar a produção, qualidade dos frutos e teores de nitrogênio foliar em maracujazeiro-amarelo sob adubação nitrogenada. Os diâmetros longitudinal e transversal são empregados para classificação do tipo de fruto em alguns mercados consumidores do Brasil. Independentemente do tratamento, os frutos produzidos no presente trabalho, quanto ao calibre, enquadram-se na classe 4 (calibre igual ou maior que 75 até 85), o que os caracteriza como frutos de qualidade, já que a escala varia de 1 a 5 (Programa Brasileiro para Melhoria dos Padrões Comerciais e Embalagens de Hortigrangeiros, 2001).

Apesar da ausência de diferença estatística, as médias de espessura de casca do maracujá-amarelo contidas na Tabela 2 são superiores às obtidas por Cavalcante et al. (2012a) e Rocha et al. (2013). Destaca-se, pertinentemente, que frutos com esta espessura de casca são, em geral, adequados para transporte a longas distâncias, em virtude de reduzirem as perdas pós-colheita por injúrias físicas.

A percentagem de polpa dos frutos de maracujazeiro-amarelo (Tabela 2) não foi influenciada pelas doses de nitrogênio e substâncias húmicas aplicadas ao solo por fertirrigação. Os valores médios de percentagem de polpa,contidos na Tabela 2 são inferiores aos registrados por Cavichioli et al. (2011) e Venâncio et al. (2013), mas bastante superiores ao encontrado por Rocha et al. (2013).

Os resultados obtidos no presente trabalho contrastam com os registrados por Vianna-Silva etal. (2010), ao inferirem que a menor espessura de casca relaciona-se com maior rendimento de polpa e, consequentemente, de suco. Nesse sentido, é necessário considerar a época em que os frutos foram colhidos, em ambos os trabalhos, pois a mudança total da cor do maracujá de verde-amarelo para amarelo tem sido recomendada como indicador do ponto de colheita, representando assim, o ponto ideal de maturidade fisiológica (Gomes et al., 2006).

Dentre as características químicas 
estudadas constata-se efeito de interação entre doses de $\mathrm{N}$ e SHs apenas para $\mathrm{pH}$ de polpa $(\mathrm{p}<$ $0,05)$ e acidez titulável (AT) ( $p<0,01)$ (Tabela 3).
Entretanto, as SHs exerceram efeito significativo sobre a relação teor de sólidos solúveis e acidez titulável (SS/AT) denominada "ratio".

Tabela 3. Características químicas [pH, vitamina C (Vit.C), sólidos solúveis (SS), acidez titulável (AT) e ratio (SS/AT)] de frutos do maracujazeiro-amarelo em função de fertirrigação com nitrogênio e substâncias húmicas.

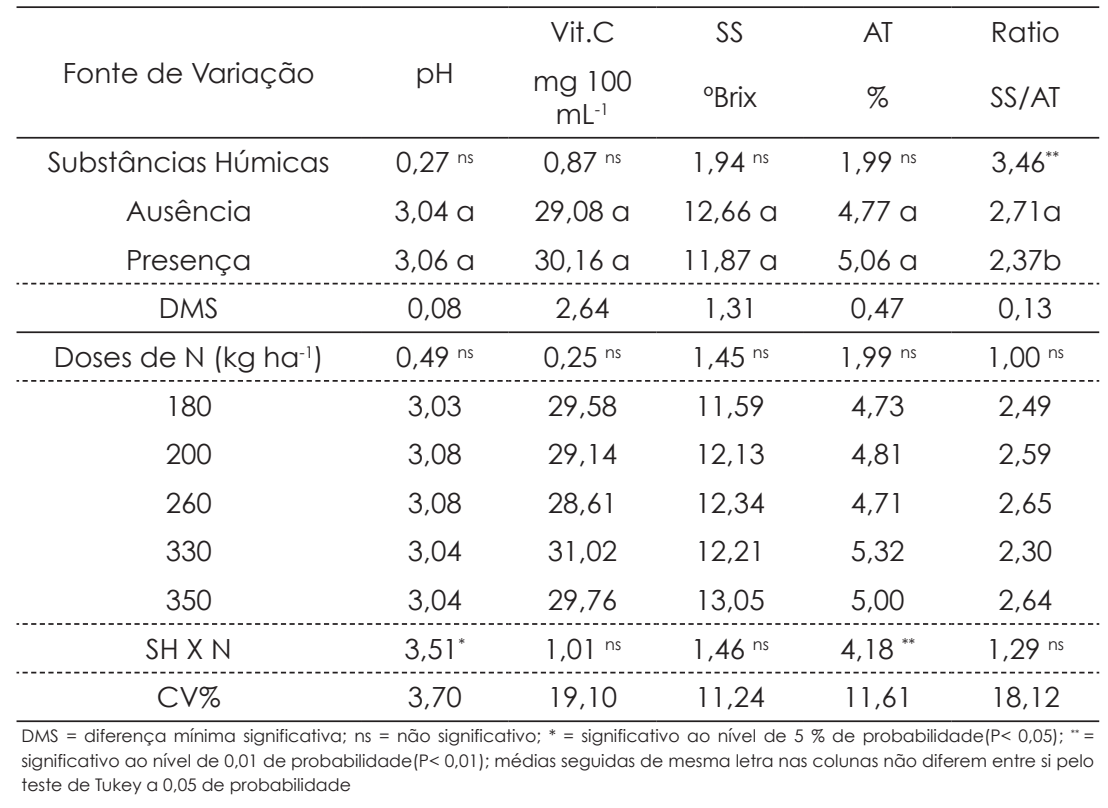

Apesar da ausência de efeito significativo para a maioria das determinações químicas contidas na Tabela 3, pode-se inferir que, conforme os valores mínimos estabelecidos na Instrução Normativa $n^{\circ} 12$ do Ministério da Agricultura Pecuária e Abastecimento (MAPA) os valores de sólidos solúveis, $\mathrm{pH}$ e acidez titulável da polpa do maracujá amarelo registrados no presente estudo são adequados para consumo tanto in natura como para indústria sucos. Essa Instrução Normativa aprova o Regulamento Técnico Geral para fixação dos padrões de identidade e qualidade para polpa de frutas e determina que a polpa de maracujá deva obedecer às características e composição como segue: Sólidos solúveis ( ${ }^{\circ} \mathrm{Brix}$ ) a $20^{\circ} \mathrm{C}(11,0)$, $\mathrm{pH}(2,7)$ e acidez total expressa em ácido cítrico (g/100g) $(2,50)$.

Conforme observado na Tabela 3, houve efeito de interação entre as doses de NeSHssobre as variáveis $\mathrm{pH}$ e acidez titulável dos frutos do maracujazeiro-amarelo. Na ausência das SHs os valores médios de $\mathrm{pH}$ dos frutos ajustaram-se ao modelo de regressão quadrático, atingindo $\mathrm{pH}$ de 3,10 com a dose máxima estimada de 225 $\mathrm{kg} \mathrm{ha}^{-1}$ de $\mathrm{N}$, decrescendo com o aumento das doses de $\mathrm{N}$ (Figura 2A). Os valores registrados nesse estudo são compatíveis aos relatados por Borges et al. (2006) no cultivo do maracujáamarelo.

Conforme se pode observar da Figura 2B, na presença das SH houve incremento de 3,85\% no $\mathrm{pH}$ dos frutos do maracujazeiro-amarelo da menor para a maior dose de $\mathrm{N}$ testada, com ajuste ao modelo linear crescente de regressão. Para Durigan et al. (2004) o pH da polpa é uma característica do fruto utilizada para avaliar o caráter ácido dos frutos e o período de vida útil pós-colheita, destacando-se que frutos menos ácidos são mais apropriados para o consumo in natura, enquanto aqueles de caráter mais ácidos são mais requeridos pela indústria de alimentos (Campos et al., 2007).

Para a acidez titulável (Figuras 2C e 2D) houveram respostas diferenciadas quanto à ausência e presença das substâncias húmicas em interação com doses de $\mathrm{N}$ aplicadas via fertirrigação. Houve decréscimo exponencial no valor da acidez dos frutos do maracujazeiroamarelo na ausência das SHs em função do aumento das doses de N(Figura $2 \mathrm{C}$ ), resultado que concorda com Cunha et al. (2015) em Bom 
Jesus,Pl, enquanto Venâncio et al. (2013) não verificaram diferença significativa para acidez titulável de frutos de maracujazeiro-amarelo submetido a adubação nitrogenada nas condições de Aquidauana-MS.

Na presença das SHs houve incremento exponencial na acidez titulável dos frutos de maracujazeiro-amarelo em função do aumento das doses de $\mathrm{N}$ aplicadas ao solo (Figura 2D), resultado divergente ao reportado por Fathy et al. (2010) que não verificaram diferença significativa entre os atributos químicos de sólidos solúveis, acidez titulável e ratio(SS/AT) de frutos de damasco 'Canino' (Prunus armeniaca L.) em função das substâncias húmicas. No entanto, os resultados do presente trabalho
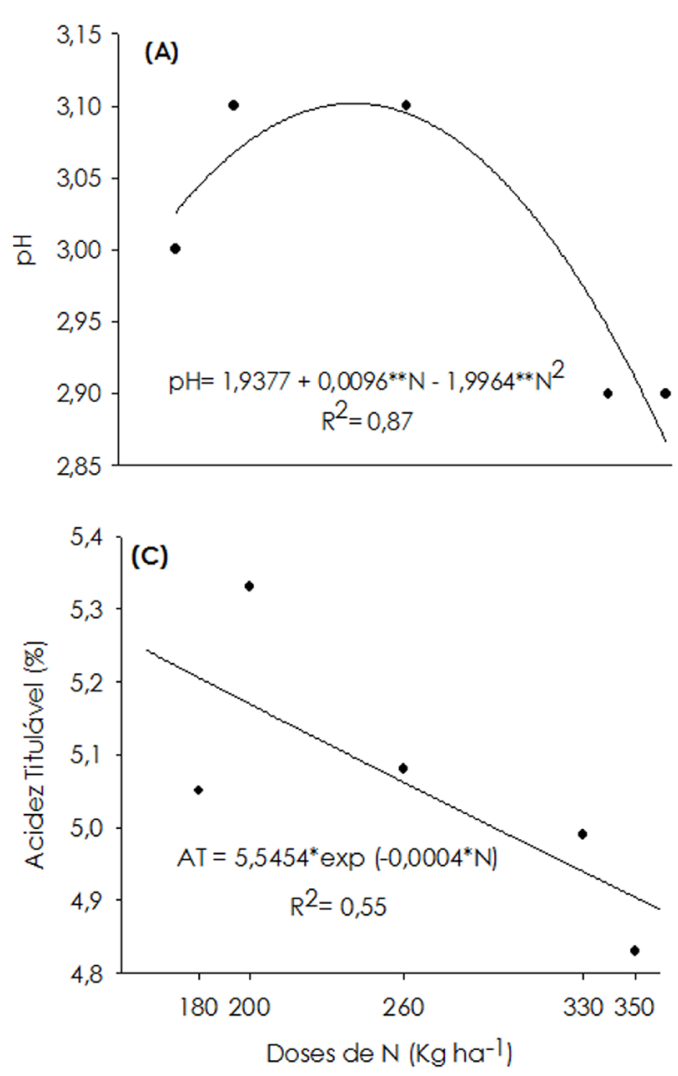

convergemcom Ferrara \& Brunetti (2010) que verificaram diferença significativa para sólidos solúveis e acidez titulável em frutos da videira cultivar Itália submetida a diferentes doses de substâncias húmicas.

O uso de SHs via fertirrigação promoveu redução significativa de $12,55 \%$ no ratio SS/AT. Segundo Raimundo et al. (2009) o ratio é uma das melhores formas de avaliar o sabor de um fruto, pois determina o balanço entre os sabores doce/ácido da polpa e quando são analisados individualmente representam um falso indicativo de qualidade de frutos. Farias et al. (2007) não verificaram diferença significativa para a relação (SS/AT) em frutos do maracujazeiroamarelo comercializado em Rio Branco, Acre.
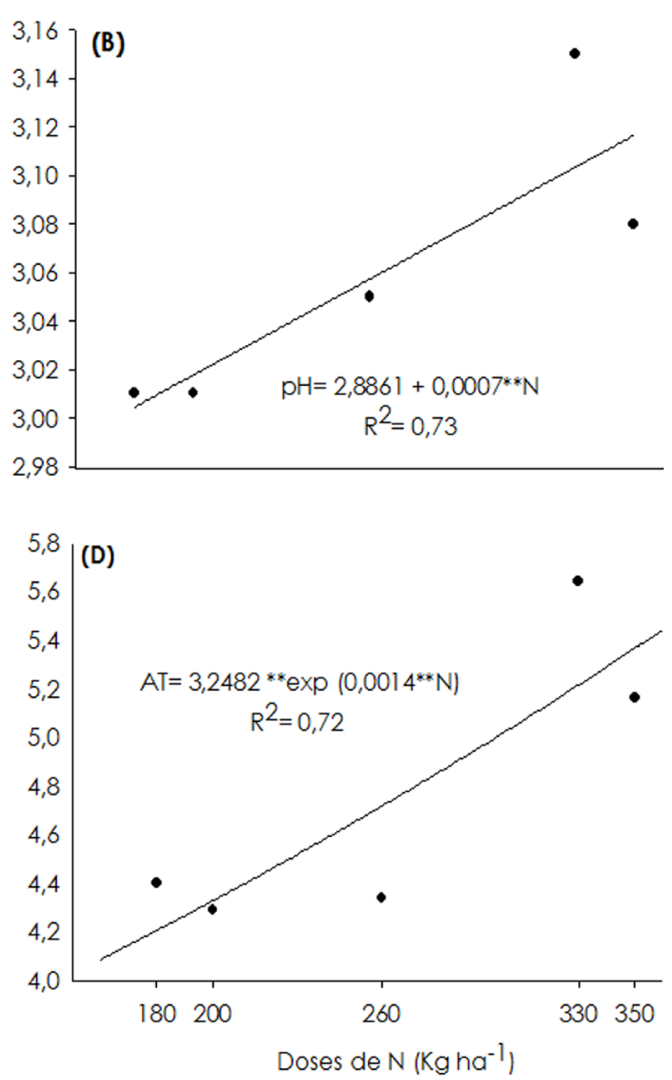

Figura 2. Valores de $\mathrm{pH}(\mathrm{A}$ e B) e acidez titulável (C e D) em frutos de maracujazeiro-amarelo em função de doses de $\mathrm{N}$ e substâncias húmicas $\mathrm{A}$ e C: sem substâncias húmicas; B e D: com substâncias húmicas.

\section{Conclusões}

Aadubaçãonitrogenadaemassociação com substâncias húmicas incrementam o pH e a acidez titulável dos frutos;

Os frutos de maracujazeiro-amarelo produzidos, independentemente do tratamento, apresentam diâmetros longitudinal e transversal, sólidos solúveis, $\mathrm{pH}$ e acidez titulável adequados para o consumo in natura ou e para indústria, conforme as normas vigentes de classificação de maracujá;

Recomenda-se a dose de $260 \mathrm{~kg} \mathrm{ha}^{-1}$ de N independente da aplicação de SHs para a produção de frutos de maracujá-amarelo com qualidade superior, conforme as normas vigentes de classificação de maracujá. 


\section{Referências}

Abreu, S.P.M., Peixoto, J.R., Junqueira, N.T.V., Sousa, M.A.F. 2009. Características físicoquímicas de cinco genótipos de maracujazeiro-azedo cultivados no Distrito Federal. Revista Brasileira de Fruticultura 31: 487-491.

Baccan, N., Andrade, J.C., Godinho, O.E., Barone, J.S. 2001. Química analítica quantitativa elementar. Edgard Blücher Ltd, São Paulo, Brasil. $324 \mathrm{p}$.

Baldotto, L.E.B., Baldotto, M.A., Giro, V.B., Canellas, L.P., Olivares, F.L., Bressan-smith, R. 2009. Desempenho do abacaxizeiro 'vitória' em resposta à aplicação de ácidos húmicos durante a aclimatação. Revista Brasileira de Ciência do Solo 33: 979-990.

Borges, A.L., Caldas, R.C., Lima, A.A. 2006. Doses e fontes de nitrogênio em fertirrigação no cultivo do maracujá-amarelo. Revista Brasileira de Fruticultura 28: 301-304.

Borges, A.L., Coelho, E.F. 2009. Fertirrigação em frutíferas tropicais. Embrapa Mandioca e Fruticultura, Cruz das Almas, Brasil. 180 p.

Bredemeier, C., Mundstock, C.M. 2000. Regulação da absorção e assimilação do nitrogênio nas plantas. Ciência Rural 30: 365-372.

Campos, V.B., Cavalcante, L.F., Dantas, T.A.G., Mota, J.K.M., Rodrigues, A.C., Diniz, A.A. 2007. Caracterização física e química de frutos de maracujazeiro amarelo sob adubação potássica, biofertilizante e cobertura morta. Revista Brasileira de Produtos Agroindustriais9: 5971.

Cavalcante, Í.H.L., Cavalcante, L.F., Santos, G.D., Beckmann-Cavalcante, M.Z., Silva, S.M. 2012a. Impact of biofertilizers on mineral status and fruit quality of yellow passion fruit in Brazil. Communications in Soil Science and Plant Analysis 43: 2027-2042.

Cavalcante, Í.H.L., Cunha, M.S., BeckmannCavalcante, M.Z.,Osajima, J.A., Souza, J.S.N. 2012b. Relationship between chlorophyll meter readings and leaf nitrogen concentration in custard apple. Philippine Journal of Crop Science 37: 88-92.

Cavalcante, Í.H.L., Cunha, M.S., Rocha, L.F., Santos, E.M., Silva Junior, G.B. 2014. Physiological indexes of custard apple as a function of nitrogen fertilizing and humic substances. Revista de Ciências Agrárias 57: 85-89.

Cavichioli, J.C., Corrêa, L.S., Boliani, A.C., Santos, P.C. 2011 . Características físicas e químicas de frutos de maracujazeiro-amarelo enxertado em três porta-enxertos. Revista Brasileira de
Fruticultura 33: 905-914.

Cavichioli, J.C., Ruggiero, C., Volpe, C.A. 2008. Caracterização físico-química de frutos de maracujazeiro-amarelo submetidos à iluminação artificial, irrigação e sombreamento. Revista Brasileira de Fruticultura 30: 649-656.

Cunha, M.S., Cavalcante, Í.H.L., Mancin, A.C., Albano, F.G., Marques, A.S. 2015. Qualidade de frutos e produção da ateira em função de adubação nitrogenada e substâncias húmicas. Acta Scientiarum. Agronomy 37: 21 1-218.

Durigan, J.F., Sigrist, J.M.M., Alves, R.E., Filgueiras, H.A.C., Vieira, G. 2004. Qualidade e tecnologia pós-colheita do maracujá. In: Lima, A.A., Cunha, M.A.P. Produção e qualidade na Passicultura. Embrapa Mandioca e Fruticultura,Cruz das Almas, Brasil. 2004. p.281-304.

Farias, J.F., Silva, L.J.B., Araújo, N.S.E., Mendonça, V. 2007. Qualidade do maracujá-amarelo comercializado em Rio Branco, Acre. Revista Caatinga 20: 196-202.

Fathy, M.A., Gabr, M.A., El shall, S.A. 2010. Effect of humic acid treatments on 'canino' apricot growth, yield and fruit quality. New York Science Journal 3: 109-115.

Ferrara, G., Brunetti, G. 2008. Influence of foliar applications of humic acids on yield and fruit quality of Table grape cv, Itália. Journal International des Sciences de la Vigneet du Vin 42: 79-87.

Ferrara, G., Brunetti, G. 2010. Effects of the times of application of a soil humic acid on berry quality of table grape (Vitis vinifera L.) cv Italia. Journal of Agricultural Research 8: 817-822.

Gomes, T.S., Chiba, H.T., Simionato, E.M.R.S., Sampaio, A.C. 2006. Qualidade da polpa de maracujá amarelo - seleção afruvec, em função das condições de armazenamento dos frutos. Alimento e Nutrição 17: 401-405.

IBGE. Instituto Brasileiro de Geografia e Estatística. Produção de maracujá. 2014. http://www.sidra. ibge.gov.br/<Acesso em 25 Mai. 2014>

Instituto Adolfo Lutz. 2008. Métodos Fisicoquimicos para análise de alimentos. Instituto Adolfo Lutz, São Paulo, Brasil. 1020 p.

Loss, A., Pereira, M.G., Bernini, T.A., Valladares, G.S. 2015. Caracterização química e hidrofóbica de organossolos e solos com horizonte hístico. Comunicata Scientiae 6: 113-122.

Programa Brasileiro para Melhoria dos Padrões Comerciais e Embalagens de Hortigrangeiros. 2001. Normas de classificação de maracujá. Centro de Qualidade em Horticultura (CEAGESP), 
São Paulo, Brasil. 2 p.

Raimundo, K., Magri, R.S., Simionato, E.M.R.S., Sampaio, A.C. 2009. Avaliação física e química da polpa de maracujá congelada comercializada na região de Bauru. Revista Brasileira de Fruticultura 31: 539-543.

Rocha, L.F., Cunha, M.S., Santos, E.M., Lima, F.N.de., Mancin, A.C., Cavalcante, Í.H.L. 2013. Biofertilizante, calagem e adubação com NK nas características físicas e químicas de frutos de maracujazeiro-amarelo. Revista Brasileira de Ciências Agrárias 8: 555-562.

Santos, G.P. dos., Lima, N.A.J., Cavalcante, L.F., Cavalcante, Í.H.L., Souto, A.G.L. 2014. Crescimento e produção do maracujazeiro amarelo sob diferentes fontes e doses de fósforo em cobertura. Bioscience Journal 30: 525-533.

Taiz, L., Zeiger, E. 2009. Fisiologia vegetal. Ed Artmed, Porto Alegre, Brasil. 848 p.

Venâncio, J.B., Rodrigues, E.T., Silveira, M.V., Araújo, W.F., Chagas, E.A., Castro, A.M. 2013. Produção, qualidade dos frutos e teores de nitrogênio foliar em maracujazeiro-amarelo sob adubação nitrogenada. Científica 41: 11-20.

Vianna-Silva, T., Lima, R.V., Azevedo, I.G., Rosa, R.C.C., Souza, M.S., Oliveira, J.G. 2010. Determinação da maturidade fisiológica de frutos de maracujazeiro-amarelo colhidos na região Norte do estado do Rio de Janeiro, Brasil. Revista Brasileira de Fruticultura 32: 57-66. 